\title{
Philippine bird taxonomy and conservation: a commentary on Peterson (2006)
}

\author{
N. J. COLLAR
}

\section{Summary}

A review by Peterson (2006) claims that a new species-level taxonomy leads to improved conservation insights for Philippine birds. However, it does not report how borderline taxonomic cases were dealt with, how many taxa and specimens were examined, how closely the evaluations were made, why four key museums were omitted from the survey, and why certain taxa were omitted despite their presence in museums visited. It provides no conclusive or accurate diagnoses in more than $40 \%$ of taxa on the first two pages of the Appendix, and overlooks another $16 \%$ that have already achieved species-level recognition. It unjustifiably asserts that work was hampered by lack of material, and inappropriately calls for the collection of a highly threatened taxon. It employs one unstable diagnostic method but preaches the virtue of another, entirely different but equally unstable. All these shortcomings undermine confidence in the paper's rigour; and reference to the recent conservation literature shows that in any case no new conservation insights have resulted.

\section{Introduction}

Peterson (2006) bills his recent evaluation of Philippine avian species-level taxonomy as "a new view" $^{\prime \prime}$ to help prevent biodiversity conservation priorities being affected by "unforeseen and unwanted biases resulting from inconsistencies among taxa". He begins and ends by instructing conservationists to "pay attention" - indeed, to "pay close attention" - to taxonomic matters and species concepts. However, his paper exhibits so many lapses of attention of its own, affecting premise, completeness, replicability, accuracy, use of others' work, analysis, results and claims, that it is impossible to let it stand without suspicion or to let it pass without commentary.

\section{Shortcomings in premise and its presentation}

Peterson's premise is that the use of species concepts (rather than taxonomy per se) exerts a significant influence over the way species' distributions determine priority areas for conservation. The possibility that this might not be the case is something he sets out to test, although his early signals (notably the fiat that prioritizing exercises "should take into account the taxonomic viewpoint ... involved") warn us in advance of the answer we can expect. This would be understandable if the case to be made were closely argued with fully presented evidence and stringent analysis, but in only his second paragraph he sets the standard for the entire paper with the remark that

the early commentary of Hazevoet (1996) arguing for the need for careful attention to species concepts in developing conservation assessments received strong rebuttal from the conservation "establishment" (Collar 1996), suggesting that the message has not been appreciated broadly. 
This is ominously inexact and incomplete. First, Hazevoet was not arguing for "careful attention to species concepts"; rather, he was attacking the biological species concept (BSC) for, in his view, condemning certain taxa to extinction by treating them as subspecies, and arguing for its replacement with the phylogenetic (read evolutionary) species concept (PSC). Second, if my rebuttal was "strong", it should have been both comprehensive and convincing, yet the implication is that the conservation "establishment" (apparently BirdLife International) remains insensitive and intractable on the point at issue. This distorts the position, which a reading of my "rebuttal" will disclose; moreover, soon afterwards I dwelt at greater length on the issue of taxonomy, species concepts and conservation, and drew what I hope was a considered conclusion on both the inherent weaknesses of the PSC and the serious impracticality of applying it wholesale and overnight to existing world lists of biological species (Collar 1997). It is therefore not at all a matter of failing to appreciate the message; it is, rather, simply that the proponents of the PSC and its variants repeatedly fail to acknowledge its fundamental problem - the inability to establish a threshold for the triviality of the characters to be considered, and hence the inability to establish a fixed basis for the consistent delineation of species.

Nothing illustrates the nature of this problem more clearly than the contradiction between Peterson's own approach to "taxonomy" in Philippine birds, which uses a simple if still ambiguous method for discriminating potential new "species taxa" (discussed next) and his concluding invocation of another PSC approach, the premise of which completely undermines the basis of his own work (see Character triviality in the PSC).

\section{Shortcomings in project framework and method}

Peterson states that "many ... species vary dramatically from island to island", but that "these differentiated forms are frequently described as subspecies of biological species, and as such may be confused with other ('minor') subspecies that are not genuinely distinct". He seemingly draws a confident line between "genuinely distinct forms" and "only subtly distinct (or not distinct!)" ones, but the single taxonomic criterion he uses in this exercise is that "differences among populations had to be discrete, permitting easy separation of essentially $100 \%$ of individuals of that age/sex from the two populations". As the basis for a taxonomic revision, this is too imprecise: Why "easy"? Why "essentially"? Why no discussion or definition of what constitutes "minor" and "subtly distinct" and even "not distinct" subspecies? What about the possibility of vocal differences between lookalike taxa? Remsen (2005) observed that the lack of rigour in this approach "recalls the heyday of the antiquated 'Peters Checklist' method", adding the key point - not dealt with in the response by Peterson and Navarro-Sigüenza (2006) - that

applying PSC rank only to highly differentiated populations that may be species under the BSC without also making an honest, thorough search for all minimum diagnosable units is not an appropriate application of the PSC.

Even when used in a "first-pass" evaluation for Peterson's immediate purposes, there are so many unanswered questions that the value of the exercise itself is greatly compromised.

To begin with, there is the plain matter of methodology and the quality of his individual assessments. If one museum held one taxon and another another, how were they compared with confidence? If not all taxa in a highly polytypic biological species were available for review, how was a decision over discrete differences between available taxa taken? When specimens were measured, how many were used to ensure that size differences were not sampling artefacts (note the reference to "woefully small samples" in the legend to the Appendix)? What was in fact measured when "body size" was assessed? How carefully were the "subtly distinct" or "minor subspecies" investigated for $100 \%$ diagnosability? Were taxa $100 \%$ diagnosable on very minor characters (shading, morphometrics) all included or all excluded? These are simple methodological points that could and should have been explicitly dealt with, yet are all left 
hanging. So when Peterson claims that "many subspecies reviewed in this effort were not distinct", we remain unclear as to which they were and how their fate was decided. This only fuels suspicion over potential "unwanted biases" of the type Peterson claims to be overcoming.

Then there is the matter of his comprehensiveness. Although he gives the number of biological species recorded (556), breeding (395) and endemic (169) in the Philippines, based on the key work of Dickinson et al. (1991) and a paper of his own (Peterson et al. 2000), Peterson fails to indicate the figure most relevant to his endeavour, namely the number of subspecies endemic to the Philippines and therefore in need of evaluation. Based on Dickinson et al. (1991) I count 631, which to my mind represents a very considerable challenge to work through. Nevertheless, Peterson asserts that "specimens of almost all named taxa of Philippine birds (Dickinson et al. 1991) were inspected in most major systematic collections from the Philippines". This sounds reassuring, yet it is (a) ambiguous (did he inspect almost all of the taxa ever described, or almost all of the taxa that happen to be represented in the collections he visited?) and (b) contradicted by the legend to his Appendix, where he laments "the unavailability of many of the key taxa". So just as we are not clear what taxonomic rigour was brought to bear in this exercise, we are given no clue as to the proportion of taxa that was in fact evaluated, despite the crucial relevance of this to the task at hand. A second source of possible bias enters the frame.

Moreover, it is troubling that some of the key collections of Philippine birds were unaccountably omitted from Peterson's researches, most notably the Smithsonian Institution, DC (USNM), Delaware Museum of Natural History, Greenville (DMNH), Cincinnati Museum of Natural History, Cincinnati (CMNH) and Carnegie Museum of Natural History, Pittsburgh (CM), particularly as all four of these institutions had staff actively describing taxa from the Philippines at various stages of the twentieth century. It is not just that these might be expected to hold individual taxa that cannot be found elsewhere - for example, the "distinctive endemic Burias subspecies" of Hypsipetes philippinus, which Dickinson et al. (1991: 52) mentioned and which can evidently only be viewed in DMNH - but rather that whole suites of such taxa might be patchily distributed in museums as they are in nature - for example, the seven subspecies known from Polillo (Mallari et al. 2001), none of which Peterson mentions - owing to the inevitably selective way in which collectors for particular museums moved among the islands. Here, then, is a third source of potential bias in the exercise.

Notable too are the omissions from Peterson's list of taxa that are represented in the museums he visited: the highly distinctive forms Micromacronus $l$. leytensis and M. l. sordidus are available for comparison in the American Museum of Natural History and possibly nowhere else on earth - certainly nowhere else in the United States (Peterson's other criterion about checking his findings at a second institution is not violated, since this only applies "whenever possible"). Where too is Gallicolumba crinigera and its 10o\% diagnosable form leytensis? Alcedo argentata and flumenicola? Nominate Ceyx melanurus? Ficedula basilanica and samarensis? Parus semilarvatus and nehrkorni? Where is Caprimulgus manillensis, which other people seem to have no difficulty in separating from celebensis (Coates and Bishop 1997, Cleere 1998, Holyoak 2001), or Surniculus velutinus, long since separated from lugubris (Payne 1997, 2005)? This list of absentees, all $100 \%$ diagnosable, results from a very quick survey of sources, including my own BirdLife file notes and the Field Museum of Natural History (FMNH) online database, to confirm that the necessary specimens are in the museums Peterson visited. So how and why were these taxa missed? Were they missed in the sense of not being examined, or in the sense of not being found to possess distinctive characters? Whatever the answers, a fourth source of bias surfaces.

\section{Shortcomings in specimen assessment and use of the literature}

In briefly now considering the accuracy and thoroughness of Peterson's exercise, one notable feature is that he appears to have relied solely on specimen evidence, without any reference to 
the literature. In one sense this seems boldly independent; in another recklessly negligent. Some key literature at least is based on a review of specimen material, and would surely have confirmed, denied, guided or refined his perceptions (or, if his perceptions show the literature to be wrong, an indication of the mistake would surely be constructive and valuable). In the review below of just the first two pages (pp.163-164) of Peterson's Appendix, which may or may not be representative of the whole but which is simply where I began and decided to end, I abbreviate all references to relevant volumes of Handbook of the birds of the world (ed. J. del Hoyo et al. 1992-present, Barcelona: Lynx Edicions) as "HBW+number". Peterson informs us that:

- Philippine populations of Aviceda jerdoni have a "whitish chest (not brown as in SE Asian forms)", but Ferguson-Lees and Christie (2001) describe the Philippine race magnirostris as "darker [than nominate jerdoni, which occurs in SE Asia], with stronger rufous barring below";

- Philippine population of Accipiter virgatus has a "solid brown wash on chest (not barred)", but Ferguson-Lees and Christie (2001) indicated that this form belongs to the largely insular "virgatus" group, which is typified by such a wash, and that this wash is just as strongly present, to the virtual exclusion of barring, in vanbemmeli (Sumatra) and abdulali (Andamans);

- populations of Microhierax erythrogenys from Greater Luzon, Mindoro and Negros are smaller than those from Greater Mindanao, with the proviso that "Bohol populations are a possible exception", but Ferguson-Lees and Christie (2001), not mentioning size, declined to recognize the southern subspecies meridionalis owing to its inconstant and peculiar patterns in both plumage and distribution (Bohol is supposed to be in the range of nominate erythrogenys while Cebu, sitting between Bohol and Negros, holds or held meridionalis);

- Philippine populations of Gallirallus philippensis are "smaller in body size than other populations", but Taylor (1998) provided measurements of all 22 subspecies which indicate that several taxa are smaller (e.g. pelewensis, xerophilus) than or similar in size (e.g. reductus, assimilis) to nominate philippensis, and he further indicated that, contra Dickinson et al. (1991) and as accepted by Dickinson (2003), philippensis is in any case not endemic to the Philippines but occurs on Sulawesi and its satellites, the Sulas, Buru and several Lesser Sunda Islands;

- Philippine populations of Rallina eurizonoides have a "cinnamon throat (not white)", but Taylor (1998) indicated this character also in minahasa of Sulawesi;

- Philippine populations of Porzana cinerea are "larger in body size", but Taylor (1998) declined to recognize any subspecific division of the species, indicating that differences between named subspecies "are slight, not well defined, [and] in most cases subject to overlap"; moreover, his measurements contradict Peterson's claim (mean wing $95.5 \mathrm{~mm}$ in Sumatra and Java, 98.2 in Sulawesi, 94 in the Philippines, 94 in Australia and New Guinea; a slightly longer bill in the Philippines appears to result from measuring tip to skull rather than exposed culmen, and in any case there is mensural overlap, which Peterson's key criterion does not allow);

- "two distinct wintering populations" of Himantopus himantopus are recorded in the Philippines, but this is completely irrelevant to an analysis of Philippine biogeography and endemism, when one subspecies (nominate himantopus) extends right across to Europe, and the other (leucocephalus) right down to New Zealand;

- northern Luzon populations of Ducula aenea "have a purple crescent on hindneck, not present in other populations", but this feature appears, albeit in different shades, in birds from the Calayan group to the north and from Sulawesi and its adjacent northern archipelagos and southern islands and on Banggai and Sula (Gibbs et al. 2001);

- populations of Prioniturus discurus from Luzon, Negros and Mindoro have blue foreheads and those from Greater Mindanao green foreheads, but in reality Mindoro birds have green foreheads and darker blue rest of crown, while all other birds have mid-blue crowns 
(including foreheads) but with Mindanao (not Greater Mindanao) birds having more blue than those to the north (HBW4, Kennedy et al. 200o);

- populations of Loriculus philippensis from Greater Mindanao "lack the orange forehead", but in reality they do not $\left(\mathrm{HBW}_{4}\right.$, Kennedy et al. 2000);

- Philippine populations of Chrysococcyx xanthorhynchus have a "rusty wash on throat and upper breast lacking in other populations", but $H_{B} W_{4}$ and Kennedy et al. (2000) indicated that (a) the dividing line falls within the Philippines (Palawan birds are like the extralimital populations), and (b) the key plumage difference lies in the former being smaller and in the adult male being violet-blue rather than violet, suggesting that Peterson may not have looked at adult males at all, a notion reinforced by the seeming improbability of their having such a rusty wash (unreported elsewhere in the literature); indeed, the plate in $\mathrm{HBW}_{4}$ suggests that the rusty wash which can be found in females may be a hepatic morphism, not a geographical character, and Payne (2005) referred to the underparts of females being "whitish (or rufous wash whitish)" without suggesting a taxonomic assortment;

- Philippine populations of Hemiprocne comata have a "large body size as compared with other populations", whereas $H_{B} W_{5}$ - although indicating several other characters that can diagnose the Philippine race major - stated that these populations "average larger, but Sumatran and Malay Peninsula birds both increase in size clinally northwards, giving much overlap between [the two] races" (hence negating Peterson's "100\% diagnosable" rule on this character);

- Philippine populations of Halcyon (Pelargopsis) capensis "differ from other populations in having the cap orange (not grey)" and medium-orange Palawan birds differ from the pale orange ones in the "rest of the Philippines", but this is to miss the orange-capped intermedia of the Nicobar Islands and to play down the distinctiveness of the whitishbodied gigantea (all illustrated in Fry et al. 1992 and HBW6);

- Greater Luzon populations of Actenoides lindsayi have "back and breast green" and those of Negros have "back and breast black", whereas Kennedy et al. (2000) indicated the difference as the former having "margins of feathers on back and wings green in [Greater Luzon] and black in [Negros]".

Thus no fewer than 14 (44\%) of 32 taxa dealt with in the first two pages of Peterson's Appendix have questions of accuracy hanging over them, while another 5 (16\%) have already been split by others (see below), suggesting that some $60 \%$ of Peterson's treatments on these pages are in some way open to query. In a half-day at the Natural History Museum, Tring (NHM), I briefly checked the 14 diagnoses above against the specimen evidence and found that (apart from and discounting the Himantopus example) Peterson is:

- mistaken in seven cases (Accipiter virgatus, Gallirallus philippensis, Rallina eurizonoides, Porzana cinerea, Prioniturus discurus, Loriculus philippensis and Hemiprocne comata, although with Hemiprocne I did not check the diagnostic features indicated in HBW);

- insufficiently clear over Aviceda jerdoni, where there is no taxonomic reason to confine comparison to South-East Asian birds, but where the small sample in NHM shows some Thai birds to be just as white-breasted as its single magnirostris;

- technically mistaken (by apparent overruling the $100 \%$ diagnosability criterion with respect to Bohol birds) but probably correct over Microhierax erythrogenys, as there is size difference in southern birds, apparently not clinal (although a considerable number of measurements would be needed to clarify the situation);

- possibly correct over Ducula aenea but unclear (it is the "purple", not the "crescent", that is or may be unique), with validation impossible since NHM lacks Calayan specimens;

- accidentally correct (male plumage very distinct, but this character not mentioned) but technically mistaken (because citing another difference that does not apply at least to the male) over Chrysococcyx xanthorhynchus, although the cited difference possibly applies to females only (NHM holds only one male and no female); 
- acceptably correct over Halcyon capensis (both Philippine taxa are evidently diagnosable) but technically mistaken since the race gigantea shows extensive grey-brown streaking on the crown (i.e. not all Philippine populations have a plain orange head), and since Nicobar intermedia is arguably also orange-crowned;

- correct over Actenoides lindsayi in terms of distinctiveness between taxa but technically incorrect in terms of description.

This level of uncertainty and inaccuracy is hardly cause for confidence: can we really be sure that Peterson has separated out "genuinely distinct forms" from "only subtly distinct (or not distinct!)" ones? One cannot help but ask how many "unforeseen and unwanted biases resulting from inconsistencies among taxa" might here be in the making as a consequence.

\section{Unsupported claims for new taxonomic insights}

One upshot of taking Dickinson et al. (1991) as his taxonomic baseline, and of not checking the literature, is that Peterson lays claim to a number of revisions which are in fact already published elsewhere. Spilornis holospilus was split by Ferguson-Lees and Christie (2001). Amaurornis olivacea was split by McAllan and Bruce (1988), followed by Sibley and Monroe (1990) and Taylor (1998). Porphyrio pulverulentus was split by Sangster (1998). Phapitreron cinereiceps and Dendocopos ramsayi were split by Collar et al. (1999). Prioniturus waterstradti was split by Sibley and Monroe (1990). Loriculus bonapartei was split by Juniper and Parr (1998). Ninox mindorensis was split by König et al. (1999). Penelopides and Aceros hornbills were split by Kemp (1988, 1995). Oriolus albiloris was split by Greenway (1962), Sibley and Monroe (1990) and, with a short justification, Collar (1998). Sitta oenochlamys was split by Gonzales and Rees (1988) and, evidently with independent assessments, by Sibley and Monroe (1990) and Harrap and Quinn (1996), followed by Inskipp et al. (1996). Dicaeum australe was split by Brooks et al. (1992) backed up by Mann (2002). Many other taxonomic issues have long been flagged for deeper consideration, such as the Chrysocolaptes woodpeckers and Dicrurus hottentotus menagei (Collar 1997, 2003), the other bar-breasted forms of Ninox philippensis (Collar and Rasmussen 1998, Collar et al. 1999: 41), Ixos siquijorensis cinereiceps (Mallari et al. 2001) and Hypsipetes everetti haynaldi (Allen 1998).

Apart from this, the publication of various global and family reviews ( $H B W$, monographs such as Kemp 1995, Cleere 1998, Taylor 1998, Gibbs et al. 2001) and in particular the recent field guide (Kennedy et al. 2000) have gone a long way towards itemizing the distinctiveness of many of the taxa with which Peterson deals. When, therefore, he claims that these taxa represent (my italics) "heretofore unrecognized distinct populations within currently recognized species", he is mistaken.

\section{Misrepresentation of specimen availability and of collecting needs}

Peterson is further mistaken in a central claim in his Discussion. There he deplores the "important impediment" to his research represented by "the paucity of bird specimens from parts of the Philippines". This leads to the following:

such incomplete representation prevented this broad survey from resulting in a complete, checked and verified list including final decisions regarding synonymy and priority.

This judgement is difficult to reconcile with the fact that Peterson omitted from his survey four of the most important collections for Philippine bird species in his own country, a failure that cannot be put down to ignorance, for the significance of these four museums is indicated passim in Dickinson et al. (1991, notably pp. 78-81), and their holdings are repeatedly mentioned in the taxonomic literature. Owing largely to the indefatigable D. S. Rabor, who collected some 60,000 
specimens (Kennedy and Miranda 1998), backed up by various collectors for the Philippine National Museum, and by Salomonsen in Copenhagen, duPont in Delaware and Kennedy in Cincinnati, no other country in South-East Asia - and, on reflection, no other country in Asia has been so extensively sampled for birds in the past half-century (I doubt whether all the other countries in Asia combined could muster 60,000 specimens taken in the period of Rabor's collecting career, roughly 1945-1985); and when this achievement is set back-to-back with the pioneering work of people such as the Platens, A. H. Everett, Steere, Whitehead, Bourns \& Worcester, McGregor, Mearns, Manuel and Hachisuka, it may well be that there is no tropical country on earth, other than India, which was so well collected in the hundred years prior to that. It is not so much that more material is needed; it is far more that the collections where existing material is held should be made better use of.

In this regard it is wholly inappropriate for Peterson to call for new material of Dicrurus hottentotus menagei to aid its taxonomic evaluation, given that this form is (a) represented in several US museums and (b) so rare in life that I had feared it extinct (Collar 1997), although it proves to be just hanging on (Allen 2006). Peterson's reference to the "unique specimen from Tablas" - presumably FMNH 20179, since the Field Museum has a single skin - is mystifying, given that (a) it is not the type (which Dickinson et al. [1991] tell us is in USNM) and (b) NHM, which Peterson lists as a museum he worked in, has two specimens. Apart from these (and discounting the type), I have seen six specimens in USNM and two in CM, and there is a co-type in the University of Michigan Museum of Zoology (UMMZ 70834; J. Hinshaw in litt. 2006), so that there are at least 13 skins available for study in American and British collections. The point about museum researchers optimizing their use of existing material of rare and threatened taxa has been made before (Snow 1972, Collar 2000), and I am sorry that it has to be made again.

\section{Character triviality in the PSC}

In drawing his analysis to a conclusion, Peterson makes a comment that undermines the endeavour behind his own paper and thereby illuminates the entire problem with the PSC:

A recent review of species limits and criteria used in describing bird species (Watson 2005) pointed out the impressive degree to which bird species are defined by ornithological taxonomists based on "field marks", in marked contrast to those used by other vertebrate zoologists. This focus on identifiable species has clearly simplified the view of bird diversity, but runs the risk of obscuring important, independent evolutionary lineages ... Workers in bird conservation should therefore pay close attention to the taxonomic basis of the species lists on which they base their conservation assessments.

Setting aside the fact that Watson (2005) produced no coherent evidence to support his argument (Collar and Spottiswoode 2005), Peterson is here commending a proposition (that focusing on the merely identifiable misses all sorts of cryptic diversity) diametrically at odds with the central method of his own paper (focusing on the merely identifiable). Unwittingly, he thus exposes the problem at the heart of the PSC: its inability to disallow the triviality of a diagnostic character, and hence to prevent the continuing taxonomic subdivision of populations. What now of Peterson's "subtly distinct" taxa, the "other ('minor') subspecies that are not genuinely distinct" and which he therefore saw fit to dismiss? Since "workers in bird conservation should ... pay close attention to the taxonomic basis of the[ir] species lists", what now of Peterson's Appendix, given that it is based entirely on "field marks", on the "easy separation" of populations? If workers in bird conservation are instead being enjoined to follow Watson (2005), who argued for the adoption in avian taxonomy of parameters used by other vertebrate zoologists such as internal morphology and molecular differentiation, why should they give even a moment's notice to the findings of Peterson (2006)? 


\section{Unsupported claims for new conservation insights}

The final consideration here is the most immediately important: does Peterson's analysis reveal something which conservationists did not already know, and which demonstrates that taxonomy in this instance really does matter? That is, after all, the entire point of the exercise. So what are his findings? (1) He points to shifts in the proportions of endemic species complements among island groups that are already identified as priorities. (2) He claims to have identified several island groups with endemic species "when few or none were known or prioritized previously" (Greater Sulus, Greater Romblon, Batanes/Babuyan Islands, Camiguin Sur, Cagayan group and Siquijor). (3) He finds areas of endemism within areas of endemism (northern vs southern Luzon; Samar, Leyte and Bohol vs Mindanao and its satellites; areas within Mindanao although the lines on his map of Mindanao are too imprecise to work out what these are). "Put simply, new conservation priorities were revealed or known areas of importance were emphasized thanks to an alternative species taxonomy." I cannot agree.

- Finding (I) is barely relevant, because priority-setters are already targeting these island groups anyway, and shifts in proportions of endemic species complements among island groups have only very limited (if any) effects on the overall levels of priority assigned to these islands.

- Finding (2) is hardly more substantial, because, as Peterson admits, these "new" island groups are for the most part already priorities, one (Greater Sulus) being an Endemic Bird Area (EBA), three (Greater Romblon, Batanes/Babuyan and Siquijor) being EBA "Secondary Areas", and one (Camiguin Sur) forming part of the Mindanao and Eastern Visayas EBA (Stattersfield et al. 1998). Moreover, the Greater Sulus contain four Important Bird Areas (IBAs), Greater Romblon two, the Batanes one, Camiguin Sur one and Siquijor one (Mallari et al. 2001). So only neglected "Cagayan" emerges here, this proving to be Cagayancillo, which holds a large subspecies of Zosterops nigrorum. And it is not as if these places, including Cagayancillo, have been ignored for their biogeographic interest or distinctiveness over the past 100 years or more (see Dickinson et al. 1991: 4850).

- Finding (3), which Peterson thinks "perhaps most interesting", covers ground which again is by no means new (see Dickinson et al. 1991: 52-53). Today the divide between northern and southern Luzon is established by, for example, the split of Stachyris dennistouni from S. nigrocapitata, the separation of Samar, Leyte and Bohol from Mindanao and its satellites by three species (Stattersfield et al. 1998), and the minor distinctiveness of western Mindanao by Ixos rufigularis. These and many other finer divisions within the Luzon EBA and the Mindanao and Eastern Visayas EBA can be found in the distribution tables in Stattersfield et al. (1998: 468, 478). In all cases a substantial number of appropriately sited IBAs exists, so that nothing is left unaddressed by present conservation priorities and no adjustments are needed.

In this regard it is worth noting that Peterson's parting comment on the IBA study "Consideration of endemic subspecies as units of conservation action (Mallari et al. 2001) would be misleading as well, as many subspecies reviewed in this effort were not distinct" - is itself as misleading as it is baffling, since Mallari et al. (2001) did not use subspecies in their analysis, but merely indicated subspecies endemic to individual IBAs which had already been identified on other criteria.

\section{Conclusion}

With the debatable exception of the large Zosterops on Cagayancillo (and, although he makes nothing of it, the division of the Batanes and Babuyanes island groups north of Luzon), no serious insights emerge in Peterson (2006) to modify the findings of Stattersfield et al. (1998) and the site priorities in Mallari et al. (2001), these latter being fleshed out in Ong et al. (2002), 
where even Cagayancillo, the Batanes and Babuyanes are separately identified for attention. However much the Philippine avifauna may be in need of taxonomic revision - and here he and I can strongly agree - Peterson is far too late with this analysis to have an impact on the biogeographic-scale conservation agenda (the work has all been done), and far too casual to have an impact on the systematic agenda (the work will all have to be done again properly); and nothing in his paper offers convincing support for his pronouncements about the importance of taxonomy, species concepts and collecting.

\section{Acknowledgements}

I am most grateful to three referees and two Associate Editors of Bird Conservation International for their comments on the original version of this paper.

\section{References}

Allen, D. (1998) On the birds of Tawi Tawi province in the Philippines. Bull. Tsurumi Univ. 35(4): 73-154.

Allen, D. (2006) New records and other observations of birds on the island of Tablas, Romblon province, Philippines. Forktail 22: 77-84.

Brooks, T. M., Evans, T. D., Dutson, G. C. L., Anderson, G. Q. A., Asane, D. C., Timmins, R. J. and Toledo, A. G. (1992) The conservation status of the birds of Negros, Philippines. Bird Conserv. Int. 2: 273-302.

Cleere, N. (1998) Nightjars: a guide to nightjars and related nightbirds. Robertsbridge, East Sussex, U.K: Pica Press.

Coates, B. J. and Bishop, K. D. (1997) A guide to the birds of Wallacea. Alderley, Queensland: Dove Publications.

Collar, N. J. (1996) Species concepts and conservation: a response to Hazevoet. Bird Conserv. Int. 6: 197-200.

Collar, N. J. (1997) Taxonomy and conservation: chicken and egg. Bull. Brit. Orn. Club 117: 122-136.

Collar, N. J. (1998) Bill morphology and the identification of Isabela Orioles Oriolus isabellae. Forktail 14: 82-84.

Collar, N. J. (2000) Collecting and conservation: cause and effect. Bird Conserv. Int. 10: 1-15.

Collar, N. J. (2003) How many bird species are there in Asia? Oriental Bird Club Bull. 38: 20-30.

Collar, N. J. and Rasmussen, P. C. (1998) Species limits in the Ninox philippensis complex. Ostrich 69: 398 (Proc. 22 Int. Orn. Congr.).

Collar, N. J. and Spottiswoode, C. N. (2005) Species limits in birds: a response to Watson. BioScience 55: 388-389.

Collar, N. J., Mallari, N. A. D. and Tabaranza, B. R. (1999) Threatened birds of the Philippines. Manila: Bookmark, Inc., in conjunction with the Haribon Foundation.

Dickinson, E. C., ed. (2003) The Howard E Moore complete checklist of the birds of the world. Third edition. London: Christopher Helm.

Dickinson, E. C., Kennedy, R. S. and Parkes, K. C. (1991) The birds of the Philippines: an annotated check-list. Tring, U.K.: British Ornithologists' Union (Check-list 12).

Ferguson-Lees, J. and Christie, D. A. (2001) Raptors of the world. London: Christopher Helm.

Fry, C. H., Fry, K. and Harris, A. (1992) Kingfishers, bee-eaters and rollers: a handbook. London: A. \& C. Black/Christopher Helm.

Gibbs, D., Barnes, E. and Cox, J. (2001) Pigeons and doves. Robertsbridge, East Sussex, U.K.: Pica Press.

Gonzales, P. C. and Rees, C. P. (1988) Birds of the Philippines. Manila: Haribon Foundation for the Conservation of Natural Resources.

Greenway, J. C. (1962) Family Oriolidae. Pp. 122-137 in E. Mayr and J. C. Greenway, eds. Check-list of birds of the 
world, 15. Cambridge, MA: Museum of Comparative Zoology.

Harrap, S. and Quinn, D. (1996) Tits, nuthatches and treecreepers. London: A. \& C. Black/Christopher Helm.

Hazevoet, C. J. (1996) Conservation and species lists: taxonomic neglect promotes the extinction of endemic birds, as exemplified by taxa from the eastern Atlantic islands. Bird Conserv. Int. 6: 181-196.

Holyoak, D. T. (2001) Nightjars and their allies: the Caprimulgiformes. Oxford: Oxford University Press (Bird Families of the World 7).

Inskipp, T., Lindsey, N. and Duckworth, W. (1996) An annotated checklist of the birds of the Oriental region. Sandy, U.K.: Oriental Bird Club.

Juniper, T. and Parr, M. (1998) Parrots: a guide to the parrots of the world. Robertsbridge, East Sussex, U.K.: Pica Press.

Kemp, A. C. (1988) The systematics and zoogeography of Oriental and Australasian hornbills (Aves: Bucerotidae). Bonn. Zool. Beitr. 39: 315-345.

Kemp, A. C. (1995) The hornbills.. Oxford: Oxford University Press (Bird Families of the World I).

Kennedy, R. S. and Miranda, H. C. (1998) In memoriam: Dioscoro S. Rabor, 1911-1996. Auk 115: 204-205.

Kennedy, R. S., Gonzales, P. C., Dickinson, E. C., Miranda, H. C. and Fisher, T. H. (200o) A guide to the birds of the Philippines. Oxford: Oxford University Press.

König, C., Weick, F. and Becking, J.-H. (1999) Owls: a guide to the owls of the world. Robertsbridge, East Sussex, U.K.: Pica Press.

Mallari, N. A. D., Tabaranza, B. R. and Crosby, M. J. (2001) Key conservation sites in the Philippines: a Haribon Foundation $\mathcal{E}$ BirdLife International directory of Important Bird Areas. Makati City, Philippines: Bookmark, Inc.

Mann, C. F. (2002) Systematic notes on Asian birds. 28. Taxonomic comments on some south-east Asian members of the family Nectariniidae. Zool. Verhand. 340: 179-189.

McAllan, I. A. W. and Bruce, M. D. (1988) The birds of New South Wales: a working list. Turramurra, Australia: Biocon Research Group.

Ong, P. S., Afuang, L. E. and Rosell-Ambal, R. G., eds. (2002) Philippine biodiversity conservation priorities: a second iteration of the National Biodiversity Strategy and Action Plan. Quezon City: Department of Environment and Natural Resources, and others.

Payne, R. B. (1997) Family Cuculidae (cuckoos). Pp. 508-607 in J. del Hoyo, A. D. Elliott and J. Sargatal, eds. Handbook of the birds of the world, 4. Barcelona: Lynx Edicions.

Payne, R. B. (2005) The cuckoos. Oxford: Oxford University Press (Bird Families of the World 15).

Peterson, A. T. (2006) Taxonomy is important in conservation: a preliminary assessment of Philippine species-level bird taxonomy. Bird Conserv. Int. 16: 155-173.

Peterson, A. T. and Navarro-Sigüenza, A. G. (2006) Consistency of taxonomic treatments: a response to Remsen (2005). Auk 123: 885-886.

Peterson, A. T., Ball, L. G. and Brady, K. W. (2000) Distribution of the birds of the Philippines: biogeography and conservation priorities. Bird Conserv. Int. 10: 149-167.

Rand, A. L. and Rabor, D. S. (1967) New birds from Luzon, Philippine Islands. Fieldiana Zool. 51: 85-89.

Remsen, J. V. (2005) Pattern, process, and rigor meet classification. Auk 122: 403-413.

Sangster, G. (1998) Purple Swamp-hen is a complex of species. Dutch Birding 20: 13-22.

Sibley, C. G. and Monroe, B. L. (1990) Distribution and taxonomy of birds of the world. New Haven: Yale University Press.

Snow, D. W. (1972) A recommendation for cooperative action by museums and private ornithological collectors, with the aim of preventing the overcollecting of rare and threatened species. Proc. XV Int. Orn. Congr.: 21-22.

Stattersfield, A. J., Crosby, M. J., Long, M. J. and Wege, D. C. (1998) Endemic Bird Areas of the world: priorities for biodiversity conservation. Cambridge, U.K.: BirdLife International (Conservation Series 7). 
Taylor, B. (1998) Rails: a guide to the rails, crakes, gallinules and coots of the world. Robertsbridge, East Sussex, U.K.: Pica Press.
Watson, D. M. (2005) Diagnosable versus distinct: evaluating species limits in birds. BioScience 55: 60-68.

\section{N. J. COLLAR}

BirdLife International, Wellbrook Court, Girton Road Cambridge CB3 oNA, U.K. E-mail:nigel.collar@birdlife.org.

Received II August 2006; revision accepted 15 November 2006 